\title{
Metástase, uma Plástica Sonora Silenciosa, ou o Regime de escuta pleno
}

Marco Scarassatti*

RESUMO: Este artigo é um estudo preliminar sobre uma categoria de instrumento musical criado por Walter Smetak. As Formas Silenciosas de Plásticas Sonoras, que aqui serão chamadas de Plásticas Sonoras Silenciosas, correspondem ao último estágio do seu processo criativo. Metástase, uma das últimas criações de Walter Smetak será analizada como dispositivo e como representação de uma ideia de educação sensível vivenciada pelo próprio Smetak no percurso de seu trabalho. Esse último estágio ainda, compreende o alcance de um estado de consciência que darei o nome de regime de escuta pleno em que o estímulo visual se converte em som na percepção.

PALAVRAS-CHAVE: escultura sonora, dispositivo, escuta, Walter Smetak

ABSTRACT: This article is a preliminary study of a musical instrument category created by Walter Smetak. The Silent shapes of Visual Sound, which here will be called the Plastic Sound Silent correspond to the last stage of his creative process. Metastasis, one of the latest creations of Walter Smetak will be analyzed as a device and as a representation of a sensitive education idea experienced by Smetak own on the course of their work. This last stage also comprises the reach of a state of consciousness that I will give a name of Full Listening Regimen where the visual stimulus is converted into sound perception.

KEYWORDS: soundsculpture, device, listening, Walter Smetak

\footnotetext{
* Marco Scarassatti é artista sonoro, compositor e professor da Universidade Federal de Minas Gerais - UFMG, desenvolve pesquisa e construção de esculturas, instalações e emblemas sonoros. Mestre em Multimeios e Doutor em Educação, ambos pela Univesidade de Campinas, é autor do livro Walter Smetak, o alquimista dos sons, editora Perspectiva/SESC, publicado em 2008.
} 
O que é estar diante de um objeto tridimensional e dele abstrair uma quarta dimensão, que seria o som?

Com essa pergunta me reaproximo de uma temática, que tangenciei na ocasião em que fiz minha pesquisa inicial sobre o pensamento e obra de Walter Smetak. A partir dela procurarei dar luz a outras questões que daí se desdobram. Essa pesquisa inicial foi editada em forma de livro (Walter Smetak: o alquimista sonoro, Ed. Perspectiva/Sesc, 2008). Naquele momento, a urgência era fabricar uma boia para que eu próprio sobrevivesse nesse oceano. Havia ali a tentativa de entender quem era esse ilustre desconhecido, a que muitos se referiam como uma espécie de guru.

Entretanto, nos discursos sobre ele, a compreensão sobre sua figura e obra situava-se, com raras exceções, no lugar-comum, no esteriótipo da excentricidade, intempestividade e misticidade que compunham a imagem do Smetak. Isso não me ajudava a acessar a obra, no sentido alquímico do Opus. Era necessário compreender quais as narrativas históricas, as poéticas e as filosóficas impregnadas nos seus objetos criados e reverberados na sua obra como um todo. Essa necessidade era também para a preservação de um acervo que vivia a eminência de se decompor por falta de espaço, por falta de um projeto mínimo de preservação.

Esse investimento pra trazer à tona um pouco do seu processo e procedimento criativo, me possibilitou conhecer o que Walter Smetak nomeou como sendo a sua última possibilidade de investigação: as Estruturas sonoras nas quais habitarão os seres criados por nós (SMETAK, 197, p.3). Ele nomeia esses últimos trabalhos como Formas Silenciosas da Plástica Sonora e aqui nesse artigo, assim como no livro, chamarei de Plásticas Sonoras Silenciosas.

Ao longo dos anos que se seguiram à escrita do livro sobre Walter Smetak, a experiência na criação de formas sonoras próprias e a experiência com a improvisação de objetos criados na obtenção de música, me ajudaram a compreender alguns outros aspectos da obra e pensamento do compositor. Entretanto, há ainda uma incompreensão que acredito só seria desfeita com um maior conhecimento e convicção, acerca da teosofia brasileira de José Henrique de Souza, a Eubiose, que reverberam nas Plásticas Sonoras smetakianas. Por isso, a reaproximação que procurarei fazer do que Smetak formula como Plástica Sonora Silenciosa, pode partir de um equívoco, que eu pretendo que seja produtivo, porque há uma questão sobre a visão de mundo, mais do que isso, há uma questão sobre o modo de estar no mundo do Smetak, que emana da sua obra, que atende a uma cosmologia própria, diria quase um perspectivismo. 
Essa pergunta, dentro de um contexto em que mais e mais artistas, se referem aos seus próprios campos poéticos, desenhando-os em torno do termo Sound Art, conduz minha atenção a uma das abordagens que delineiam a escultura sonora Metástase, do compositor suíço Walter Smetak. Smetak, ao longo de seu percurso inventivo, constituidor do que chamamos sua obra, partiu da ideia de se criar novos instrumentos musicais para um novo mundo, os subvertendo em escultura, objeto tridimensional situado entre a potência visual e a potência sonora. E chegou, inclusive, a estruturas em que a potência sonora expressava-se pelas forças de visualidade desse objeto.

Metástase é a representação plástica de um pensamento que Walter Smetak passa desenvolver e que, posteriormente nomeia como sendo o último estágio de sua obra. Ela é composta de materialidade, visualidade, e mais que isso, é composta de uma narrativa simbólica e literária, em torno do som como manifestação de um universo mítico.

Atingem os últimos trabalhos formas silenciosas da Plástica Sonora, nas quais o espectador pode se libertar de todo quanto possível ao que ele se prende ainda, para criar seu 'status quo. (SMETAK, 1977, p.3)

As Plásticas Sonoras Silenciosas seriam para Smetak, uma categoria de instrumento (instruir - mentes, segundo o autor), em que todo o espaço interior e exterior expressaria o SOM, isto é, teria a potência de afecção para atuar na enunciação de um momento em que aquele que está diante desse objeto tridimensional conseguiria abstrair a quarta dimensão, que para o compositor suíço, seria o SOM.

Mais que isso, as Plásticas Sonoras smetakianas de uma maneira geral atuam como dispositivos, no sentido que o filósofo italiano Giorgio Agambem enuncia como um conjunto de estratégias materiais ou não, linguísticas e não linguísticas que condicionam certos tipos de saber ao mesmo tempo em que são condicionados por ele.

Agamben discorre no ensaio O que é um dispositivo, sobre a importância da terminologia na filosofia e se refere a ela, provavelmente numa citação velada a Heidegger, como momento poético do pensamento. Desta feita, parte do termo técnico que ele considera decisivo na estratégia de pensamento do Michel Foucault, para formular o conceito dispositivo numa perspectiva própria. 
Chamarei literalmente de dispositivo qualquer coisa que tenha de algum modo a capacidade de capturar, orientar, determinar, interceptar, modelar, controlar e assegurar os gestos, condutas, as opiniões e os discursos dos seres viventes. (AGAMBEN, 2009, p.40)

Walter Smetak decompôs a palavra instrumento em duas partes, para delas fazer surgir o "instru" e "mentes". E assim, formula com neologismo próprio a sua apropriação do português, um sentido para a sua arte como sendo, uma instrutora de mentes.

E o que faz o instrumento musical se não isso? Capturar, orientar, interceptar, modelar, controlar e assegurar os gestos de quem os toca? De um lado, o conceito de música produz o dispositivo que a "toca" e, de outro, o dispositivo instrumento musical tece a rede simbólica e ideológica que conceitua e produz a própria música, implicando também num processo de subjetivação, isto é, a música produz o sujeito a faz.

O dispositivo/instrumento é permanentemente revisado no contato com outros dispositivos dessa rede formante do que é o fazer musical, num processo de autorregulação em que ele aparece como resultante do cruzamento dessas relações, que são antes de mais nada, relações de poder e saber. Tomo aqui a Plástica Sonora como um paradigma para o instrumento musical tradicional.

Entender o objeto Plástica Sonora como um instrutor de mentes o distancia, talvez na mesma medida em que o aproxima, da relação que se estabelece diante da obra, por exemplo, The sounds of Silence (1988) do artista norteamericano Christian Marclay.

Marclay emoldura o EP de vinil The sounds of Silence da dulpa Simon e Garfunkel, sucesso musical dos anos 60, para tomá-lo como signo e meio (mídia) para a criação, seja na relação estabelecida com a materialidade, com a visualidade, com a cultura partilhada e com uma historicidade do próprio meio (Disco de Vinil) e sua relação como registro de uma época. História e Cultura. Diante do disco de vinil da dupla norteamericana, quem conhece essa música da dupla, é levado a uma abstração e imaginação musical, fazendo-a soar como memória da canção. Quem viveu, ou conhece o período e as motivações de quando e como foi composta a canção, escutará ainda os rumores dessa época marcada pelo assassinato do presidente norteamericano Jonh Kenedy. 


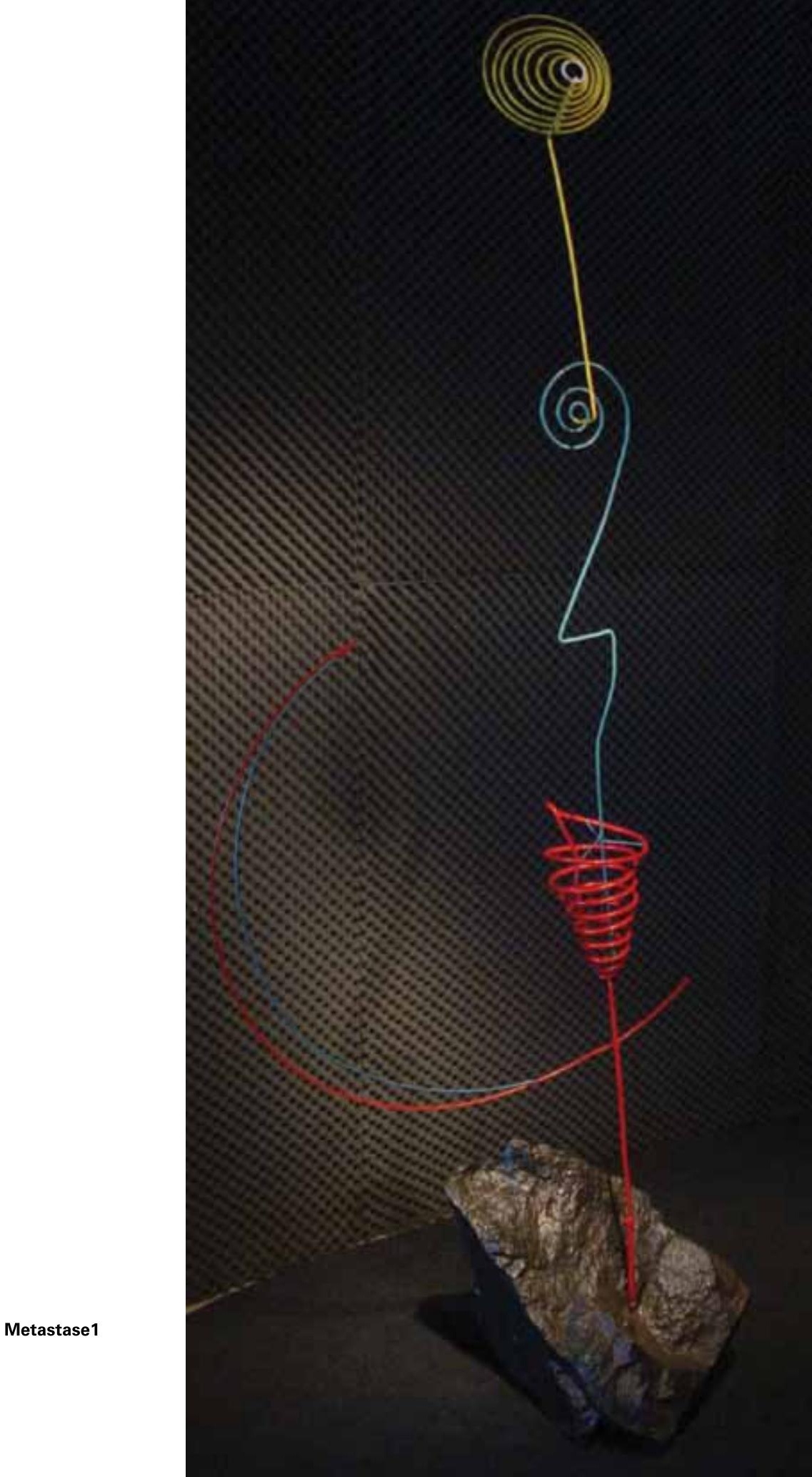


É interessante também conhecer a narrativa do ressignificante Marclay acerca dessa obra:

Minhas peças estão em silêncio, de modo que você pode preencher o espaço em branco. Eu quero que as pessoas usem a sua memória, sua própria memória. A memória nesse momento é o nosso dispositivo de gravação. Então, ao invés de da imposição de uma memória padronizada como a gravação, nós temos nossas memórias pessoais, que são mais seletivas. (FERGUSON, 2003, p.19) ${ }^{1}$

Embora Smetak opere o signo e a sua criação de outra maneira, penso que a natureza da relação é a mesma: dar caminhos para que o dispositivo seja apreendido por um sentido perceptivo e, a partir daí, deflagrar uma sistêmica poética que o formule em outro sentido perceptivo.

Na criação e constituição do dispositivo como tal, o compositor suíço emprega um procedimento próximo ao que faz com as palavras (no caso partição do instru-mento). Dentro do universo material e imaterial que está a sua volta, que compõe seu universo e cosmologia, decompõe, combina, aproxima. Procedimento muito próximo ao que Claude Lévi-Strauss formula no livro O Pensamento Selvagem, acerca do bricoleur. atua e arranja-se sempre num meio-limite, isto é, utiliza sempre de um conjunto finito de utensílios, de materiais e, porque não dizer de pensamentos, bastante heteróclitos. Ele não subordina suas construções à obtenção de matérias primas, ao contrário, ele re-arranja seus materiais e, neles, descobre e redescobre as relações que constituem sua narrativa simbólica e, porque não dizer, cosmogênica.

A cada escolha que faz, Smetak parece intencionar que o dispositivo esteja impregnado de partículas sêmicas, mitológicas e poéticas que lhe são armazenadas como potência de afecção, num processo que eu arriscaria chamar, dada a licença pela poeisis bricoler do suíço, de polisseminal.

São muitas sementes, sentidos e não é a toa que ele reiteradamente se refira à cabaça como uma sementeira, como semeadora de mentes. E de sua materialidade e forma física ele estrutura boa parte das suas plásticas sonoras; a ideia de que a cabaça carrega as sementes em seu interior, abre um campo de possibilidades voltadas para um microuniverso representado pelos microtons. Para Smetak, a esperança está na semente, a semente está no microtom. (SMETAK, 1982, p.1)

No momento em que reflete sobre isto, parte do instrumento tradicional e adentra ao seu interior, descobrindo os mistérios do som em um foco microscópico. Expande e explode a 
forma para, depois, nesse estágio, voltar à tona revelando não mais a forma do instrumento mas, sim, a do som. A interatividade é subjetiva e cada um, com a sua experiência, interioriza a própria música. Ouvir e ver o som, através de uma experiência silenciosa.

Em Metástase, plástica sonora com aproximadamente 2,50 metros, um vergalhão de ferro fincado numa pedra, parte verticalmente iniciando um percurso em direção a sua outra extremidade. Nesse percurso sai da pedra na cor vermelha, que para Smetak, numa referência à Doutrina Secreta de Helena Blavatski, ressoa a nota Dó, regida por Marte e ligada à vida animal, mundana. Seria o momento atual do mundo.

O vergalhão sofre a interferência de um outro vergalhão pintado de vermelho e azul, na forma de uma lua minguante. Após essa interferência o vergalhão se espiraliza formando um cone vermelho que se abre. De dentro dessa espiral cônica vermelha parte um vergalhão pintado de azul e que se movimenta, como a representação de um raio, até se espiralar novamente. Azul anil, regido pelo Sol e que ressoa a nota Fá. Esta cor vincula-se ao Corpo áurico, segundo o suíço. Do vórtice da espiral azul, que se assemelha a uma voluta, o vergalhão parte agora amarelo numa reta ascendente até se espiralar novamente. O amarelo seria a representação, em cor, da Alma espiritual, fazendo soar a nota Mi e regida por Mercúrio.

Para Smetak, estas três etapas cumpridas na aplicação da espiral - transformação, superação e metástase - simbolizam a evolução transcendental. A primeira espiral indica o crescimento físico até o rompimento da vida em um mergulho nas profundidades do não-ser, em uma nova forma de existência. Imagina o percurso do átomo vindo do reino mineral - a pedra. Conscientizando-se no vermelho em direção à primeira espiral. Sobe como chama sagrada até que se apaga na morte para despertar num mergulho ao subconsciente. Deixa-se levar sob a influência da lua, que parte antes da primeira espiral. Esta primeira fase seria, segundo o autor, mais dedicada ao crescimento físico e intelectual e ao desenvolvimento da razão. Lança-se, vertiginosamente, à espiral do som, a voluta do violino, de cor azul.

Smetak coloca esta fase como sendo a da preparação da evolução espiritual, para se chegar ao último estágio, a cor amarela. Nesse último estágio, o átomo funde-se com os outros átomos na formação de uma consciência divina. 


\section{Regime de Escuta Pleno}

Embora a discussão sobre a Escuta não seja algo que mobilize a atenção de Walter Smetak ela sempre está presente, porém ele nunca a nomeia como uma discussão; ainda assim, eu nomearia esse paradigma smetakiano como o do estabelecimento de um regime de escuta pleno.

O regime de escuta pleno seria, portanto, uma instância em que o aparelho perceptivo, no instante em que reage ao estímulo exterior, converte esse estímulo em som. A pele, como superfície de contato com o mundo, captaria todos os perceptos táteis, ou visuais, ou olfativos, ou auditivos, para transformá-los em som interiorizado, atomizado, dentro do corpo, sem escapar a ele (como perturbação acústica), o que produziria uma energia de vibração permanente.

Conjecturar um estágio em que o ser humano atinja o regime de escuta pleno, a partir de uma Plástica Sonora Silenciosa, me faz supor que a invenção e construção do novo instrumento, para Smetak, é também uma invenção e construção de um outro ser humano. Faz supor também que ele atue sobre quem estiver em relação a ele.

No manuscrito Ante projeto-projeção: O som da música não programado por meios naturais, escrito e datado por Walter Smetak em 25 de abril de 1977, o autor suíço faz uma reflexão retrospectiva da sua obra, para formular um novo projeto de pesquisa, provavelmente para um programa de pós-graduação. Nesse escrito, pondera sobre seu trabalho como um percurso percorrido:

Os seres, a sua criação, mudos-estáticos num espaço mental podem começar a movimentar-se, seja pela luz ou pelo som (...). Um rico campo de vibrações e frequências vem à tona e reanima as formas aparentemente mortas.

Assim o "brilho" do Ser se manifesta no "estar" do Ser.

Assim foi percorrido o trabalho dos instrumentos, incluindo no processo o intermediário = a pessoa-instrumento, enchendo espaços vazios para espaços cheios e, também, vice-versa: esvaziando espaços cheios, completos de remanências.

Nesta evolução os objetos criados ganharam o nome de Plásticas Sonoras e começaram a circular em exposições. Nelas se notava uma identicidade de forma-som. (SMETAK, 1977, p. 2) 
Smetak continua o texto percorrendo e refletindo sobre os estágios da sua relação com o instrumento musical inventado e convertido em Plásticas Sonoras. A criação do objeto compreenderia também um aprendizado sobre ele, no tempo de coexistência com ele:

Apareceram quase por encanto os instrumentos rotativos (cinéticos), qual deram uma conclusão nova que se prolongou nos trabalhos, para um determinado tempo de exploração, que a Inidade de ritmo, melodia (desenho horizontal) e a harmonia, dependem da rotação, fixando-se na Ronda e ante-Ronda. (SMETAK, 1977, p. 3)

A coexistência e convívio com o seu próprio invento cinético, a Ronda, desdobra-se na longa pesquisa com os microtons. Smetak fala na percepção dos microtons, assim como fala na percepção do universo como uma improvisação que se ajusta, fala também em diversidade compondo uma unidade. Essas temáticas são presentes em outros dos seus trabalhos. A improvisação ganha um tempo da sua dedicação poética, seja nas práticas sonoras ou literárias. O mesmo se dá com o universo microtonal.

Nesse escrito sobre seu trabalho percorrido, Smetak dá a impressão de entender suas Plásticas Sonoras como seres, que ao entrarem em contato o mundo material, dialogariam e trocariam experiências sensíveis, com quem os tocasse, ou interagisse com eles. Esses seres-formas seriam pensamentos, idéias, como o autor coloca no seu livro O Retorno ao futuro, (ao espirito):

O pensamento do pensador, de agora em diante, não terá mais a função que lhe deram antes. Ele deve ser o construtor de formas. Uma longa disciplina se anuncia: reter o pensamento, para obter dele a permanência da IDEIA. O IDEAL REAL é a alma (da mente), construindo o seu campo-corpo para se manifestar em plenitude. Daí, não pensar, mas sim fazer. (SMETAK, 1982, p. 27)

Voltando ao texto Ante Projeto-Projeção, Smetak parte da percepção do microtom para ampliar a escala do campo-corpo criado. E assim adentra no interior de uma Plástica sonora: surge o projeto Ovo, um estúdio em formato oval, com 22 metros de altura. Nesse estúdio o som nunca escaparia de seu interior e, seja pelas reflexões internas ou pela série de cordas simpáticas, essa vibração sonora, nunca cessaria. Nele, se o tomarmos o OVO como uma metáfora do próprio lugar em que se gesta um novo ser, ganha força a suposição de que para Smetak a invenção e construção do novo instrumento é também uma invenção e construção de um outro ser humano e que esse objeto atua sobre quem interage com ele. 

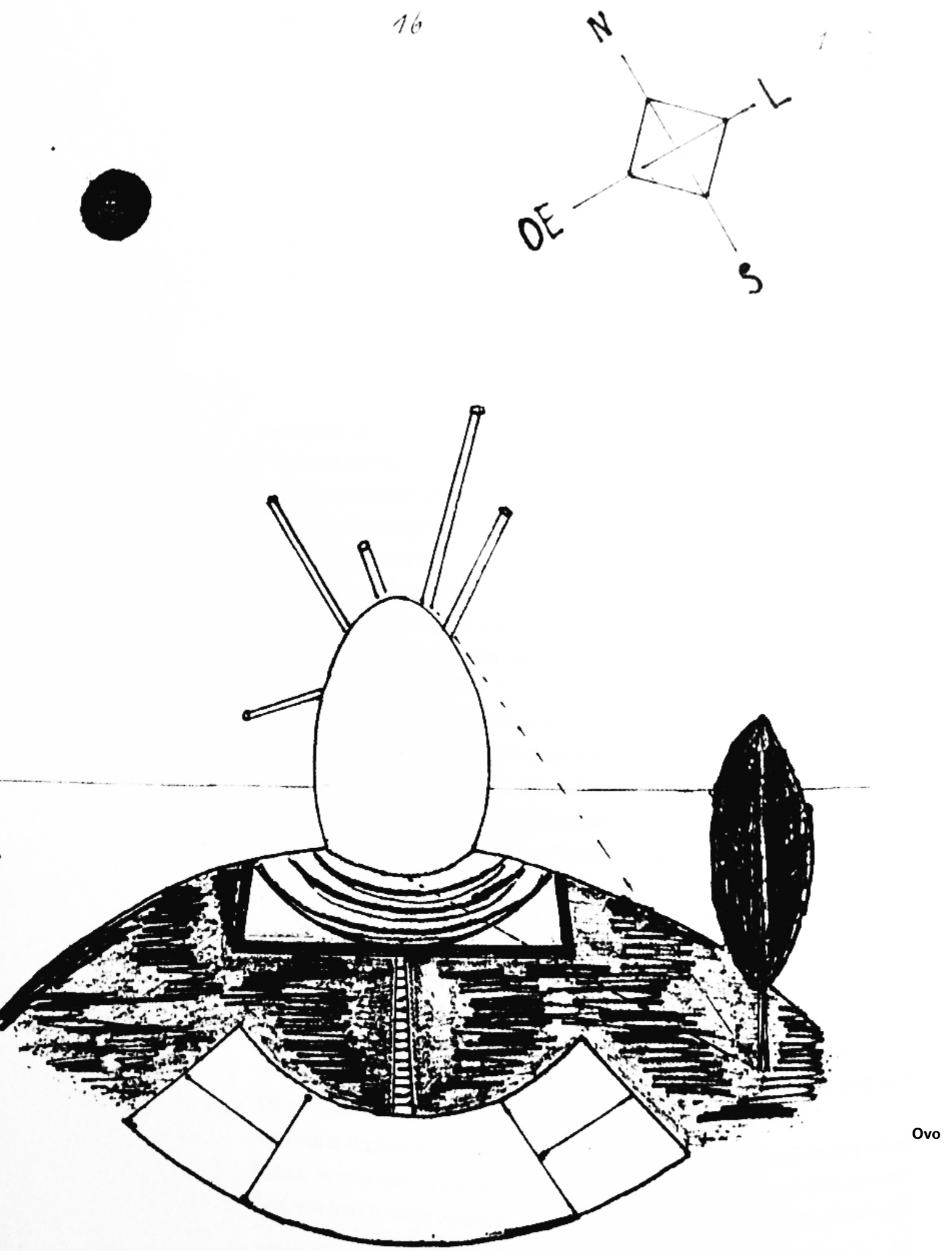
entre Ahata Nad, que seria o som físico, se propaga pelo ar, perceptível aos nossos ouvidos; e Anahata Nad, que seria o som não percebido pelos nossos ouvidos, mas sim pelo chakra Anahata. Sua propagação se dá pelo éter.

$\mathrm{Na}$ busca da forma como exteriorização do som interno, desde a construção do seu primeiro instrumento, o Mundo, até a ideia da Plástica Sonora Silenciosa, Smetak atinge o regime de escuta que o faz dispensar o instrumento como objeto, para pensá-lo como sujeito, como ser, como humano.

Destaca-se aqui uma nova função do criador-intérprete. O caminho do sujeito, do subjetivo para a objetividade do seu SER. Mas não é só isso, é muito mais. Suponhamos que o primeiro encontro com o som desse a dança dos povos; o segundo encontro, a meditação, o prelúdio, e o terceiro que vem agora, seja levado pela energia do som além da sua velocidade, à luz interna, externa e eterna. Com este processo podemos fechar o ciclo da música contemporânea, entrando assim a música, com o som que a envolve, na última fase que é puramente espiritual, hiperfísica e sem instrumento algum, mas sim com AQUELE que é e sempre foi: o próprio HOMEM. (SMETAK, 1982, p. 21)

A trajetória de Walter Smetak é o desenho de uma ideia de educação sensível, em que o estudante parte do instrumento musical tradicional, para a invenção e experimentação do instrumento com inspiração das tradições milenares, para a experiência de se construir, movimentar e tocar um instrumento cinético; para a partir dele investigar a os microtons, em dois sentidos: um no sistema microtonal que faz produzir uma intervalação que ressoa nos indivíduos e outro, no microtom como atomização do som, isto é, o som transformado na menor partícula constituinte dos seres. Do microtom, o estudante experienciaria o projeto Ovo, que é uma construção ampliada de um corpo, para provocar nele um som, que não sairia do interior de sua caixa, mas que faria vibrar a sua superfície externa. Do Ovo, à Harpa Eólia e a consciência de que uma luz pode fazer ressoar um corpo em repouso, ou invertendo, que há som em uma forma plástica. As diferenças entre cores e formas, conscientizam para eles os intervalos sonoros, a ideia de escuta permanece contida.

Aprendemos que a segunda, voltando a ser nona, significaria levar o conflito da dissonância humana ao plano do conflito metafísico, enfrentado pelo homem onde a vida se transforma em arte, onde há transformação (modulação), sendo daí em diante, Superação e finalmente, Metástase, ou seja, a identificação com o objeto. (SMETAK, 1982, p. 20) 
Formar um conhecimento técnico, que o LUGAR em que ressou o SOM tem a função de um segundo instrumento e pode ser variável na sua estruturação e no mesmo tempo ser móvel na cubagem interna. Não tendo o som possibilidade de sair para for a, ele é obrigado circular por dentro e se repercutir em diversos obstáculos de um sistema de sons simpáticos SMETAK, 1977, p. 8)

Mais do que estar falando do Ovo, penso que ele fala aqui, da relação sensível que se estabelece entre a fonte sonora e o lugar em que a perturbação acústica ressoa, e por que não dizer, a relação entre a fonte sonora e a pessoa que é afetada pela experiência com o objeto. Não a toa Smetak fala em avatarização pelo som, que permaneceria como vibração interna ao sujeito. Esse som, simbólica e acusticamente, não escaparia a ele, assim como no estúdio Ovo.

O esvaziamento da persona permitirá o processo do personare, isto é, que a pessoa seja atravessada pelo som, ou avatarizada por ele. (SMETAK, 1982, p. 16)

Adiante nesse texto, Smetak prossegue seu itinerário com a descoberta da Harpa Eólica antiga, um instrumento tocado pelo vento, que faz o compositor suíço escrever que ela lhe deu a prova do quanto som e vida se escondem nos instrumentos em repouso, que são os objetos. A Harpa aparece também em outro manuscrito, o Projeto da sala de música, escrito em 1978, e dá a entender, que nesse caso, essa Harpa Eólica, assim como o Ovo não foi, construída:

A pesquisa nos levou a uma observação interessantíssima, proveniente da antiga Harpa Eólica (instrumento tocado pelo vento): a riqueza dos sons, dentro e fora da caixa sonora, são tão extraordinários em matéria de reverberação, que este material quase não cabe na percepção humana e não podem ser inventados porque escapam à imaginação. (SMETAK, 1978, p. 6)

A atenção de Smetak já havia se deslocado para a sonoridade interna dos instrumentos, isso desde a da audição espontânea das cordas de um violão, que pendurado num varal, era tocado pelo vento. Um fragmento dessa gravação pode ser encontrado no disco Smetak, de 1974. Smetak faz questão de pontuar que embora ele não tenha concretizado sua construção, o estudo dessa Harpa milenar, o permitiu entender que a vida e o som se escondem nos instrumentos em repouso. E desse entendimento chegou no que seria o último estágio de sua pesquisa, as Formas Silenciosas da Plástica Sonora.

Essa descoberta dá um contorno para muitas das inquietações ao longo de sua trajetória, escritos, pensamentos, construções e inventos, expressos na pergunta que ele se faz: 
Deve ser reeducado o homem a ver em formas concretas que agem nas 3 dimensões, uma quarta dimensão que seria o Som pessoal daquela Gestault (forma)? (SMETAK, 1977, p. 4)

No sentido desta pergunta, haveria um propósito, uma busca delineável no itinerário investigativo, que compõem a obra de Walter Smetak? A impressão que tenho dos seus escritos do período de 1977 a 1984, é que Smetak passa a fazer uma reflexão sobre sua trajetória e conjunto da obra, e no que essa trajetória própria o afetou. Seu processo de criação tal qual um processo de individuação, com a obra atuando sobre o autor como parte desse processo. Estar diante de um objeto tridimensional e dele abstrair o Som como uma quarta dimensão, tornou-se o seu próprio paradigma, o que deu norte aos seus caminhos e buscas, à edificação de um pensamento estruturante e à constituição de um modo de se pensar e de se estar no mundo.

Transcorrer esse percurso o fez atingir, o que aqui eu esbocei ser, um regime de escuta pleno. Isso corresponde ao processo alquímico, tal qual estudado por Carl Jung, em que o processo de transformação da matéria é a repetição da obra de criação divina (2003:231) e durante o qual não só a matéria se transforma, mas o próprio alquimista. Para Smetak, compete à música dar prova concreta do abstrato. Na execução de suas Plásticas Sonoras, a sua atuação sobre a matéria, do ponto de vista construtivo, o fez percorrer um caminho criativo que o levou à abstração e dispensa do instrumento musical, tal qual o conhecemos:

É em verdade um ouvir-vendo, ou melhor, um escutar vedantino. Esta surdez requer muita solidão e só poderá acontecer na margem da sociedade. E esta solidão requer um certo relaxamento dos sentidos e reclama a ausência do PENSAR. (SMETAK, 1980)

Essa forma de surdez a que se refere é o estado de consciência que Smetak protesta e para o qual indaga se a música seria a intermediária para atingi-lo. É o regime de escuta pleno.

... Teremos assim, para a nossa imaginação sonora, a continuidade dos graves nos infrassons, e dos agudos nos ultrassons, com as suas frequencias matemáticas permitindo a sua contemplação, sendo eles os fatores do "silêncio". (SMETAK, 1982, p.19)

O silêncio para Smetak é parte do fenômeno sonoro já que considera o som como um fenômeno físico e audível e também como silêncio. (SMETAK, 1982, p.16) Para ele, a música acontece no plano físico, audível e num plano metafísico/inaudível como AKISUM. Encontramos uma correspondência a esse pensamento, na distinção também feita, pela música indiana, 

Essa ideia de educação, que se desenha na própria trajetória poética de Walter Smetak, atinge sua consciência como tal, na descoberta da Plástica Sonora Silenciosa. Nesse momento, o iniciado atinge o Regime de Escuta Pleno. O compositor suíço naturalizado brasileiro dispensa o instrumento, dispensa a música, pelo menos a física, para se dedicar ao silêncio, a música metafísica.

Esse percurso, tomado como uma proposta de educação sensível, faz reacender o interesse nesse vasto oceano, no qual a Metástase é a representação de um estado de escuta pleno, assim como os demais instrumentos criados por Smetak são dispositivos dessa educação sensível.

\section{Notas}

1 My pieces are silent, so that you can fill in the blank. I want people tu use their memory, their own memory. Memory is our now recording device, so instead of imposing a standardized memory like a record, we have our own personal memories, which are more selective.

\section{Referências}

AGAMBEN, Giorgio, O que é o contemporâneo? E outros ensaios. Chapecó-SC: Argos, 2009.

FERGUSON, Russel; KAHN, Douglas; KWON, Miwon; LICHT, Alan. Christian Marclay. Los Angeles: UCLA Hammer Museum, 2003. JUNG, C. G. Estudos alquímicos. Petrópolis: ed. Vozes, 2003.

LÉVI-STRAUSS, Claude. O pensamento selvagem. Campinas/SP: ed. Papirus, 1997. MARSICANO, Alberto. A Música Clássica da Índia. São Paulo: Editora Perspectiva, 2006. SCARASSATTI, Marco A. F. Walter Smetak: o Alquimista dos Sons. São Paulo: Editora Perspectiva/Edições Sesc, 2008 SMETAK, Walter. Simbologia dos instrumentos. Salvador: ed. Omar G., 2001. O retorno ao Futuro. Salvador: Associação dos amigos de Smetak, 1982. Carta para Guilherme Vaz, 1980, manuscrito. Projeto da sala música. Salvador, 1978, manuscrito. Ante Projeto Projeção: O som da música não programado por meios naturais. Salvador, 1977, manuscrito. 